\title{
Sumoylation of the Tumor Suppressor Promyelocytic Leukemia Protein Regulates Arsenic Trioxide-Induced Collagen Synthesis in Osteoblasts
}

\author{
Wen-Xiao Xu $\mathrm{Xu}^{\mathrm{a}, \mathrm{c}}$ Sheng-Zhi Liu ${ }^{\mathrm{b}}$ Di Wu ${ }^{\mathrm{b}}$ Guo-Fen Qiaob,c Jinglong Yan ${ }^{\mathrm{a}}$ \\ aDepartment of Orthopedics, the Second Affiliated Hospital, Harbin Medical University, Harbin, \\ ${ }^{b}$ Department of Pharmacology, Harbin Medical University, Harbin, 'Key Laboratory of Cardiovascular \\ Medicine Research, Ministry of Education, Harbin Medical University, Harbin, China
}

\section{Key Words}

Promyelocytic leukemia -Sumoylation - Osteoblasts $•$ Collagen synthesis $•$ Arsenic trioxide $•$ RNF4 • UBC9

\begin{abstract}
Background/Aims: Promyelocytic leukemia (PML) protein is a tumor suppressor that fuses with retinoic acid receptor- $\alpha$ (PML-RAR $\alpha$ ) to contribute to the initiation of acute promyelocytic leukemia (APL). Arsenic trioxide (ATO) upregulates expression of TGF- $\beta 1$, promoting collagen synthesis in osteoblasts, and ATO binds directly to PML to induce oligomerization, sumoylation, and ubiquitination. However, how ATO upregulates TGF- $\beta 1$ expression is uncertain. Thus, we suggested that PML sumoylation is responsible for regulation of TGF- $\beta 1$ protein expression. Methods: Kunming mice were treated with ATO, and osteoblasts were counted under scanning electron microscopy. Masson's staining was used to quantify collagen content. hFOB1.19 cells were transfected with siRNA against UBC9 or RNF4, and then treated with ATO or FBS. TGF- $\beta 1$, PML expression, and sumoylation were quantified with Western blot, and collagen quantified via immunocytochemistry. Results: ATO enhanced osteoblast accumulation, collagen synthesis, and PML-NB formation in vivo. Knocking down UBC9 in hFOB1.19 cells inhibited ATO- and FBS-induced PML sumoylation, TGF- $\beta 1$ expression, and collagen synthesis. Conversely, knocking down RNF4 enhanced ATO- and FBS-induced PML sumoylation, TGF- $\beta 1$ expression, and collagen synthesis. Conclusion: These data suggest that PML sumoylation is required for ATO-induced collagen synthesis in osteoblasts.

Copyright (c) 2015 S. Karger AG, Basel
\end{abstract}

\section{Introduction}

Promyelocytic leukemia (PML) is a tumor suppressor protein that was first recognized as part of a fusion protein with retinoic acid receptor- $\alpha$ (PML-RAR $\alpha$ ). This fusion protein

Jinglong Yan

and Guo-Fen Qiao

KARGER 125
Department of Orthopedics, the Second Affiliated Hospital, Harbin Medical University, \#249 Xue-Fu Road, Nan-Gang District, Harbin 150081, (PR China), E-mail yjl_8899@163.com and Department of Pharmacology, Harbin Medical University, Harbin, and Key Laboratory of Cardiovascular Medicine Research, Ministry of Education, Harbin Medical University, Harbin, (China) 
is caused by the chromosomal aberration $t(18,20)$, which plays a role in initiating acute promyelocytic leukemia (APL) [1] by blocking hematopoietic progenitor cell differentiation [2]. As such, many treatments for APL are targeted at disrupting this fusion protein or its downstream signaling [3, 4]. In normal cells, PML forms discrete structures known as PML nuclear bodies (PML-NBs) together with a variety of other proteins such as p53, SUM0-1, and Daxx [5]. PML-NBs play critical roles in a variety of cellular processes. Furthermore, recent experiments using MEFs from $P M L^{-/-}$knockout mice revealed that PML regulates cell migration, adhesion, proliferation, and morphology [6].

The transforming growth factor (TGF)- $\beta$ signaling pathway plays a critical role in maintaining cellular homeostasis by regulating processes such as apoptosis, senescence, differentiation, and growth inhibition. Altered TGF- $\beta$ signaling has been implicated in the development or progression of a variety of cancers, such as colon, breast, pancreatic, prostate, and leukemia, including APL [7]. Interestingly, several studies have reported links between TGF- $\beta$ and PML. For example, cytoplasmic PML regulates TGF- $\beta$ signaling, and cells lacking PML are insensitive to TGF- $\beta$-induced growth arrest [8].

Arsenic trioxide $\left(\mathrm{As}_{2} \mathrm{O}_{3}\right.$; ATO $)$ is an antitumor agent that is used to treat a variety of tumors, including APL, myelodysplastic syndrome, multiple myeloma, as well as solid tumors [9]. It is particularly effective against cells that harbor the PML-RAR $\alpha$ fusion protein [10]. Previous studies revealed that ATO could induce the differentiation of an APL cell line that harbors the $t(15,17)$ chromosomal aberration by inducing the sumoylation of PML$\operatorname{RAR} \alpha[11,12]$. Sumoylation is a process that conjugates ubiquitin-like polypeptides named SUMO (small ubiquitin-related modifier) onto target proteins, which regulates a variety of physiological process including transcription, DNA repair and replication, the cell cycle, apoptosis, nucleocytoplasmic transport, and ribosome synthesis $[13,14]$. Sumoylated PML then recruits the SUMO-dependent ubiquitin ligase, which leads to the ubiquitination and proteasomal degradation of PML-RAR $\alpha$ [12].

Bone is a complex tissue that is composed of multiple cell types, including osteoclasts, osteoblasts, and osteocytes, and is also remodeled continuously for renewal and repair [1517]. During this process osteoblasts generate collagen, which contributes to the formation of new bone. Previous studies revealed that ATO induces DNA tailing and causes oxidative stress in primary osteoblasts, and subsequently modulates the function and differentiation of osteoblasts $[18,19]$. Conversely, another study demonstrated that ATO induces endoplasmic reticulum stress and subsequent apoptosis in osteoblasts; therefore, the authors concluded that it ATO might cause conditions such as osteoporosis by altering bone formation. As such, the role of ATO in bone is controversial [20].

We demonstrated recently that ATO upregulated the expression of TGF- $\beta 1$ protein and promoted collagen synthesis in osteoblasts in vitro [21]. Furthermore, ATO increased TGF- $\beta 1$ synthesis and secretion in guinea pigs in vivo [22], and upregulated TGF- $\beta 1$ expression to induce apoptosis in cardiac fibroblasts [23]. However, the mechanism by which ATO upregulates TGF- $\beta 1$ expression remains unknown. Furthermore, ATO binds directly to PML to induce its oligomerization to enhance the interaction between PML and the SUMOconjugating enzyme UBC9, which increases the sumoylation and subsequent degradation of PML [24]. Because PML induced the sumoylation and formation of PML-nuclear bodies, we hypothesized that PML sumoylation regulates TGF- $\beta 1$ protein expression.

\section{Materials and Methods}

Reagents and SiRNA

ATO was purchased from Harbin YI-DA (Harbin, China). Fetal bovine serum (FBS) was obtained from Gibco (Beijing, China). siRNAs against UBC9 and RNF4 were purchased from GenePharma (Suzhou, China), and sequences are presented in Table 1. All culture media were obtained from Hyclone (Logan, UT). 


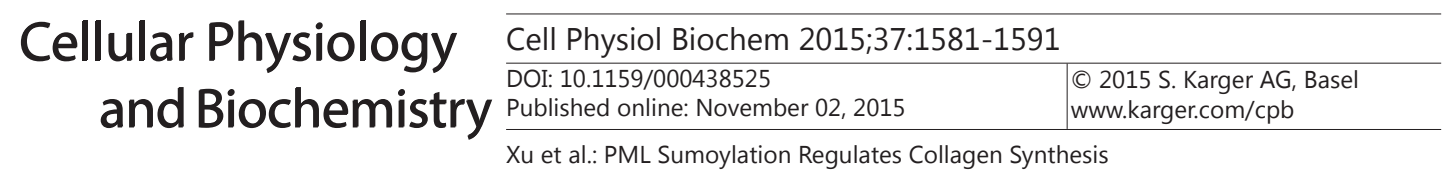

Table 1. siRNA sequences used in the current study

\begin{tabular}{ll}
\hline siRNA & Sequence (5' to $\left.3^{\prime}\right)$ \\
\hline UBC9 & Sense: CCA UCA CAA UCA AAC AGA UTT \\
& Antisense: AUC UGU UUG AUU GUG AUG GTT \\
RNF4 & $\begin{array}{l}\text { Sense: GGU GGA GCA AUA AAU UCU ATT } \\
\text { NC }\end{array}$ \\
& $\begin{array}{l}\text { Antisense: UAG AAU UUA UUG CUC CAC CTT } \\
\text { Antisense: ACG UGA CAC GUU CGG AGA ATT }\end{array}$ \\
\hline
\end{tabular}

Cell culture

The human osteoblast hFOB1.19 cell line was purchased from the Chinese Academy of Sciences (Shanghai, China), and cells were cultured in complete culture medium containing $0.3 \mathrm{mg} / \mathrm{ml} \mathrm{G418} \mathrm{in} \mathrm{F12}$ medium with $10 \% \mathrm{FBS}$ at $34^{\circ} \mathrm{C}$ under $5 \% \mathrm{CO}_{2}$. Any non-adherent cells were removed with media changes and adherent cells were retained in the culture dish for further growth. Media were changed every 3 days, as described previously [21].

Western blotting

hFOB1.19 cells were lysed in SDS buffer containing protease inhibitors (Huatesheng Biotechnology, Fushun, China) and isolated proteins were separated by SDS-PAGE and electro-transferred to nitrocellulose membranes which were incubated overnignt at $4^{\circ} \mathrm{C}$ with the following primary antibody dilutions: PML (Santa Cruz, CA), SUM01 (Santa Cruz), SUM02/3 (Invitrogen, Carlsbad, CA), TGF- $\beta 1$ (Abcam, Shanghai, China), UBC9 (Cell Signaling Technologies, Danvers, MA), RNF4 (Cell Signaling), $\beta$-actin (Research Diagnostics Inc., Flanders, NJ), and Gap (Research Diagnostics). After washing, membranes were incubated with the appropriate secondary antibodies (goat anti-rabbit and -mouse IgG; Abcam). Protein expression was quantified using Odyssey V3.0 software (LI-COR, Lincoln, NE).

\section{Immunofluorescent staining}

hFOB1.19 cells were cultured in six-well plates on glass cover slips and transfected with expression plasmids (GenePharma, Suzhou, China) using Lipofectamine 2000 (Invitrogen, Beijing, China) according to the manufacturer's instructions. Six hours after transfection the culture media were switched to media containing 10\% FBS but lacking penicillin-streptomycin, and cells were cultured for an additional $12 \mathrm{~h}$. Cells were fixed $15 \mathrm{~min}$ after transfection using 4\% paraformaldehyde in PBS for $20 \mathrm{~min}$, and permeabilized using $0.5 \%$ Triton X-100 in PBS for 10 min. They were then blocked using 4\% BSA in PBS for 20 min prior to incubation with mouse anti-PML antibodies (Santa Cruz) and Alexa 488-conjugated secondary antibodies (Invitrogen). Stained cells were mounted onto glass slides using Shandon Immu-Mount (Thermo Fisher Scientific, location) containing DAPI to visualize cell nuclei. Confocal laser microscopy was performed using an Olympus microscope (Tokyo, Japan) and the presence of PML-NBs was determined using Fluoview software v.5.0 (Olympus).

\section{Collagen measurement}

hFOB1.19 cells were cultured in six-well plates and transfected as described above. Total collagen content was determined by using a Sircol ${ }^{\mathrm{TM}}$ Collagen Assay kit (Biocolor Ltd., Northern Ireland) as described previously [21, 22]. Briefly, 0.05 M Tris buffer (pH 7.5) was used to lyse cells, and $1 \mathrm{~mL}$ of Sircol Dye reagent was used to stain the lysate $(100 \mathrm{~mL}$ ).Contents were mixed for $30 \mathrm{~min}$ and centrifuged for $10 \mathrm{~min}$ (at $>10,000 \times g$ ) to pellet the bound dye. Each tube received $1 \mathrm{~mL}$ of the alkali reagent to dissolve the bound dye, and the absorbance value was read at $540 \mathrm{~nm}$. Collagen content (mg) was converted to protein units using the linear calibration curve generated from standards (Vitrogen 100; Angiotech Biomaterials, Palo Alto, CA, USA) and was normalized to the total protein (mg) of each sample.

\section{Animals}

Mice were obtained from the Experimental Animal Center of Harbin Medical University (Grade II). Food and water were available freely throughout all experiments. Male Kunming mice weighting 20-25 g were divided randomly into three groups ( $\mathrm{n}=6$ /group): controls, experimental animals treated with $1 \mathrm{mg} /$ 
kg ATO (IV via tail vein every other day for 1 week), or experimental animals $1 \mathrm{mg} / \mathrm{kg}$ ATO (IV via tail vein every other day for 2 weeks). At the end of the treatment period mice were anaesthetized with sodium pentobarbitone $(40 \mathrm{mg} / \mathrm{kg}$, i.p.) and xylazine $(12.5 \mathrm{mg} / \mathrm{kg}$, i.p.), and anesthetic efficacy was confirmed by the absence of a tail pinch withdrawal.

Histological analyses and electron microscopy

Femurs were harvested from all mice at the end of the experiment (at 1 and 2 weeks) and bone crosssections were fixed in $4 \%$ formalin and decalcified by incubation in EDTA-2Na for 2 weeks. Hematoxylin and eosin (H\&E) staining was applied to visualize osteoblasts as reported previously [25], and Masson's staining with transmission electron microscopy (TEM) was used to quantify collagen using routine methods [26]. Finally, scanning electron microscopy (SEM) was used to assess osteoblast differentiation.

\section{Statistical analysis}

Data are presented as means \pm standard deviations (SDs). Differences between groups were evaluated using Student's $t$-tests, and $P<0.05$ was used to define statistically significant differences. Statistical analyses were performed using GraphPad Prism 5 software (La Jolla, CA).

\section{Results}

ATO promotes collagen synthesis and stimulates PML-NB formation in bone tissue

To assess the effects of ATO on bone histology, collagen synthesis, and PML sumoylation in vivo, Kunming mice femurs were harvested and analyzed using Masson's staining and EM. Figure $1 \mathrm{~A}$ shows that control femurs had little collagen accumulation, and that most osteoblasts were pre-osteoblasts (left panels). However, ATO increased collagen accumulation significantly in a time-dependent manner, as indicated by increased staining sections in mice treated for 1 and 2 weeks (Fig. $1 \mathrm{~A}$ upper panels and $1 \mathrm{~B} ; P<0.05$ ). Furthermore, ATO increased osteoblast formation in a time-dependent manner. After 1-week treatment, occasional bone cells were observed and the endoplasmic reticulum was developed. These effects were greater in mice that received ATO for 2 weeks, in which osteocytes covered most of the surface of the trabecular bone (Fig. 1A; lower panel).

Because studies suggest that PML protein and nuclear bodies (PML-NBs) formation play instrumental roles in tumor suppression $[27,28]$ and that ATO treatment leads to PML degradation and enhances PML-NBs formation [29, 30], we performed immunohistochemical staining for PML in control and ATO-treated mice (Fig. 1C). Data show that ATO increased PML-NBs formation slightly after both 1 and 2 weeks.

\section{ATO and FBS induce PML sumoylation and PML-NB formation}

Because previous data revealed that ATO stimulated PML sumoylation and subsequent degradation [29, 31], we measured PML sumoylation in hF0B1.19 human osteoblasts. Data revealed that expression of high molecular weight forms of PML (>110 kDa) increased in parallel with SUMO-1 and SUMO-2/3 as cells were incubated with ATO and FBS over time. Thus, ATO increased PML sumoylation, consistent with previous reports [32, 33].

Data to assess the effects of ATO on PML-NBs formation in hFOB1.19 cells (Fig. 2C), show that both FBS and ATO increased PML-NBs formation compared with control cells; however, ATO had a greater effect.

Knocking down UBC9 prevents ATO- and FBS-induced PML sumoylation

Because UBC9 is a SUMO-conjugating enzyme [34], we investigated its role in ATOand FBS-induced PML sumoylation. Western blot confirmed that UBC9 expression was reduced significantly $(\sim 60 \%)$ compared with untransfected (ctl) and NC-transfected cells (Fig. 3A; $P<0.05$ ). Transfecting hFOB1.19 cells with si-UBC9 alone had no effect on PML expression or sumoylation (Fig. 3B). As expected, treatment with ATO for $4 \mathrm{~h}$ increased PML expression and sumoylation in control and NC-transfected cells (Fig. 3B). However, these 


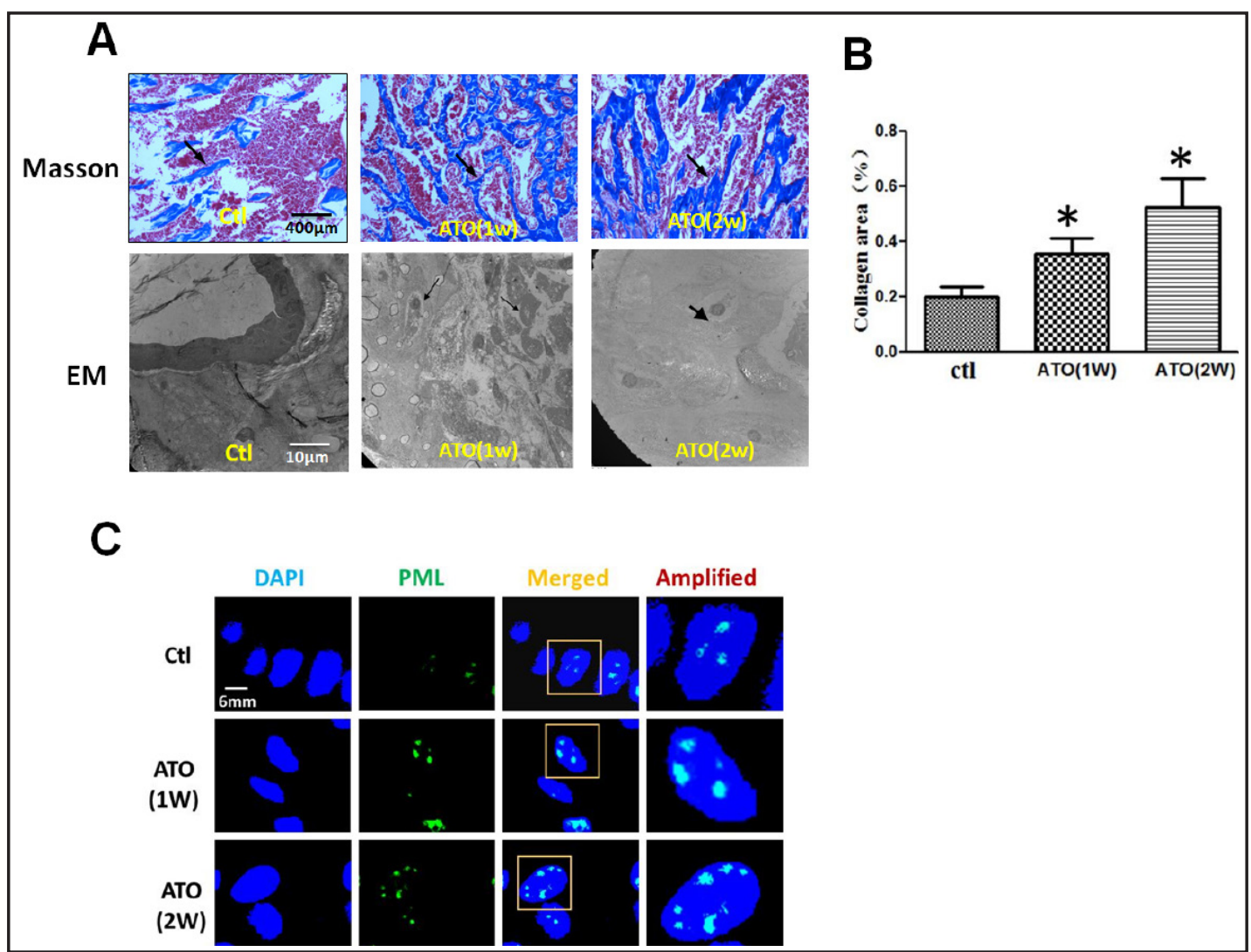

Fig. 1. ATO promotes collagen synthesis and stimulates PML-NBs formation in bone tissue. Kunming mice were treated as described in Materials and Methods. Femur tissue was visualized with Masson's staining and EM (A and B). Arrows in the upper and lower panels of A indicate collagen and osteoblasts, respectively. Immunohistochemical staining for PML (green) in the bones of control and ATO-treated mice; sections were counterstained with DAPI (blue) to visualize the cell nuclei (C). ${ }^{*} P<0.05$ vs. ctl.

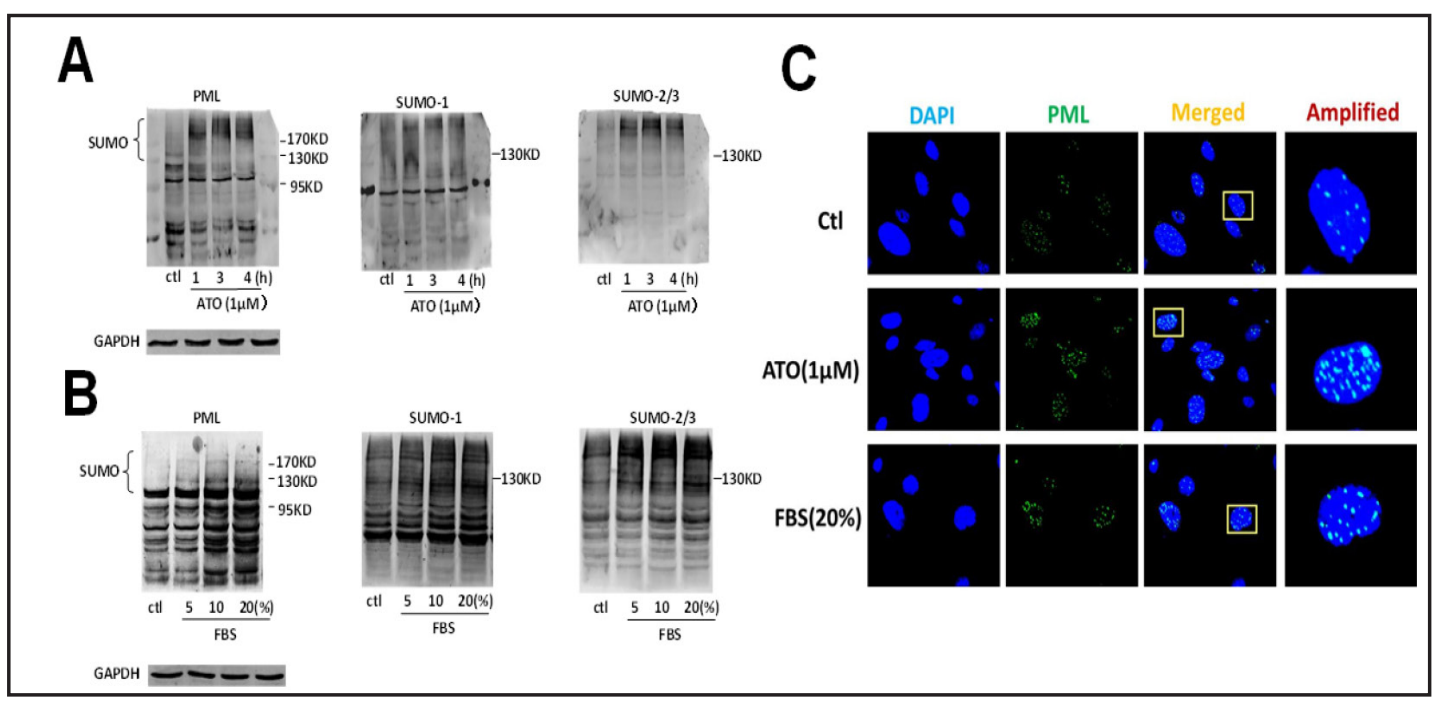

Fig. 2. ATO and FBS induce PML sumoylation and PML-NBs formation. hFOB1.19 human osteoblasts were treated as described in Materials and Methods (0,1, 3, or $4 \mathrm{~h}(\mathrm{~A})$ or $10 \%$ FBS for $12 \mathrm{~h}(\mathrm{~B})$ ), and analyzed with antibodies against PML, SUMO-1, and SUMO-2/3; GAPDH was used as a loading control. (C) Cells were treated as depicted in Materials and Methods and PML-NBs formation was measured immunofluorescently (green); sections were counterstained with DAPI (blue) to visualize the cell nuclei, $\mathrm{n}=3$.

\section{KARGER}




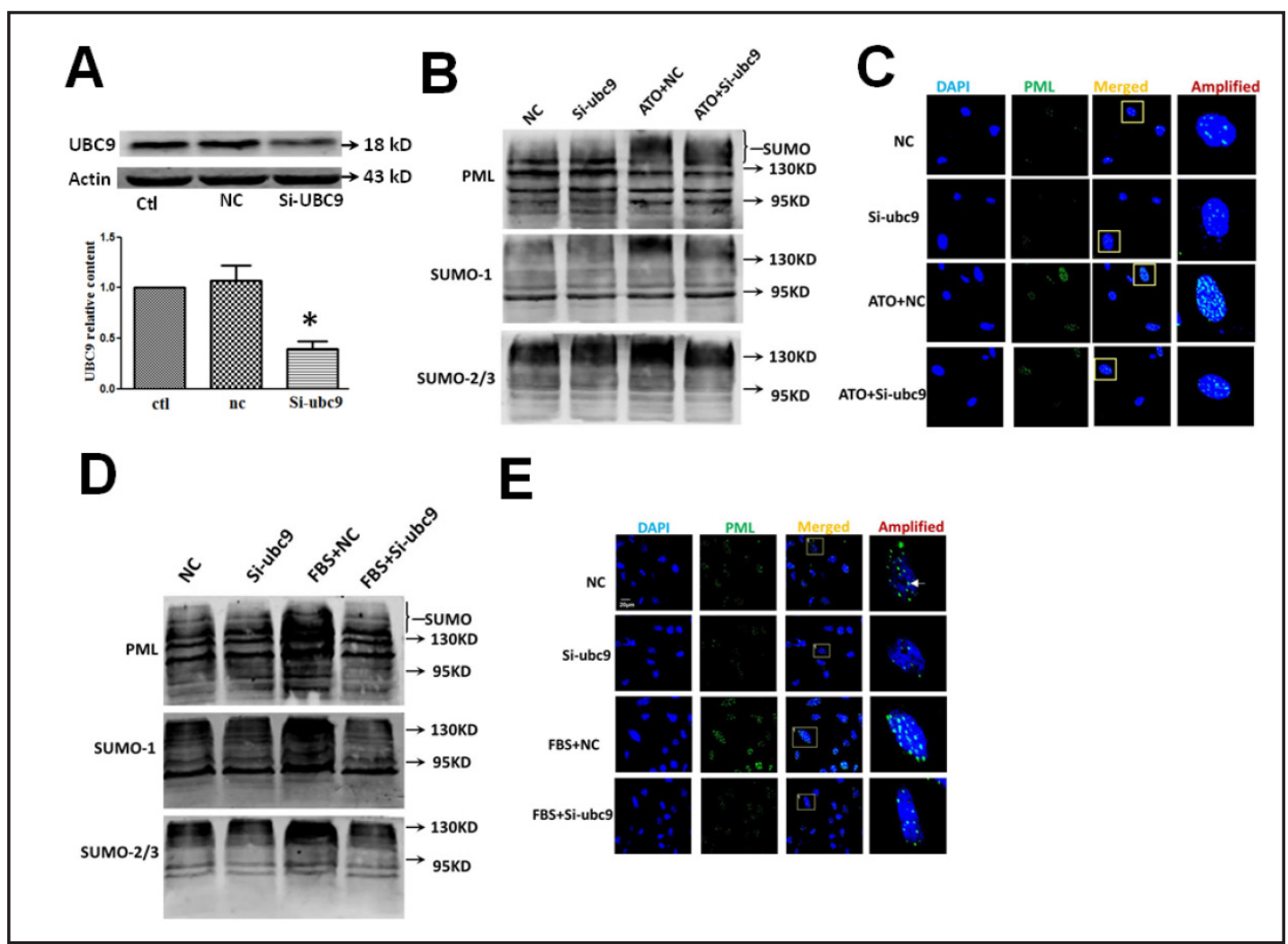

Fig. 3. Successful knockdown of UBC9 using siRNA. hFOB1.19 cells were transfected with scrambled control (NC)- or ubc9-siRNA, and UBC9 expression was measured with Western blot. $\beta$-actin was used as a loading control (A). Knocking down UBC9 prevents ATO- and FBS-induced PML sumoylation. hFOB1.19 cells were transfected as depicted and treated with ATO (B, C) or FBS (D, E). PML expression and sumoylation were measured with Western blot (B, D), and PML-NBs formation was measured immunofluorescently (green); sections were counterstained with DAPI (blue) to visualize the cell nuclei (C, E), n = 3 .

effects were reduced in cells transfected with si-UBC9. Similar effects were observed in FBStreated hFOB1.19 cells (Fig. 3D). Specifically, FBS treatment increased PML expression and sumoylation, and these effects were reduced in cells that had been pre-transfected with si-UBC9. Transfection studies with si-UBC9 alone had no effect on PML-NBs formation, as expected (Fig. 3C and 3E). However, transfection with si-UBC9 but not NC inhibited both ATO- (Fig. 3C) and FBS-induced (Fig. 3E) PML-NBs formation.

\section{Knocking down UBC9 reduced ATO- and FBS-induced TGF- $\beta 1$ expression and collagen} synthesis

ATO is reported to upregulate TGF- $\beta 1$ expression $[21,22]$ and UBC9 is thought to regulate TGF- $\beta$ expression and signaling [35]. So we used transfection studies to assess scrambled control (NC)- or UBC9-siRNA treated with ATO (Fig. 4A) or FBS (Fig. 4B). TGF- $\beta 1$ was measured and we concluded that transfection with si-UBC9 had no effect on TGF- $\beta 1$ expression. Also, ATO and FBS both increased TGF- $\beta 1$ expression significantly compared with control cells $(P<0.05)$; however, both ATO- and FBS-induced TGF- $\beta 1$ expression was inhibited be pre-transfection with si-UBC9 (Fig. 4A, B).

To learn whether UBC9 was important for ATO- and FBS-induced collagen synthesis in cultured osteoblasts, hFOB1.19 cells were treated with either FBS or ATO and relative collagen content increased significantly compared with control cells (both $P<0.05$ ). These effects were inhibited significantly by pre-transfection with si-UBC9.

\section{KARGER}




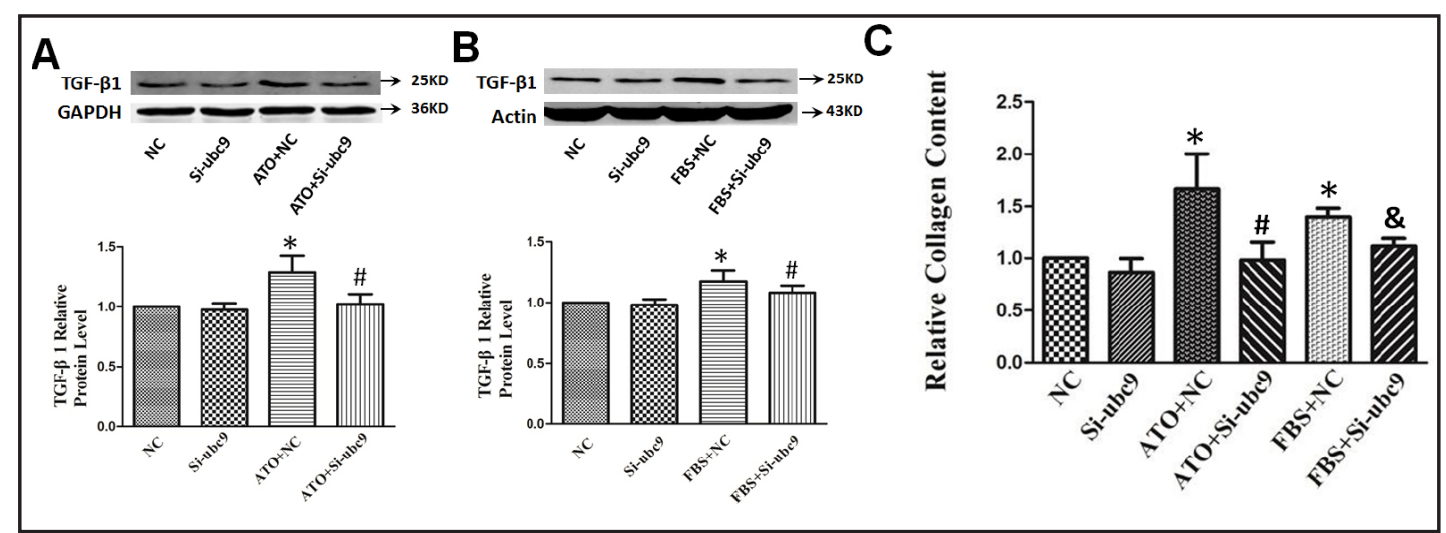

Fig. 4. Knocking down UBC9 reduced ATO- and FBS-induced TGF- $\beta 1$ expression and collagen synthesis. hFOB1.19 cells were transfected as described and treated with ATO (A) or FBS (B). TGF- $\beta 1$ was measured with Western blot (A, B), and collagen synthesis was measured as depicted in Materials and Methods (C). $* P<0.05$ vs NC; \#, $P<0.05$ vs ATO+NC; $\&, P<0.05$ vs FBS+NC, $\mathrm{n}=3$.

Knocking down RNF4 promotes ATO- and FBS-induced PML sumoylation

RNF4 is an E3 ubiquitin ligase that ubiquitinates sumoylated PML in PML-NBs [12] ro we investigated its role in ATO-induced PML sumoylation. After knockdown of RNF4 with specific siRNA (si-RNF4), hFOB1.19 cells were transfected with scrambled control (NC)- or RNF4-siRNA, and Western blot confirmed that RNF4 expression was reduced significantly $(\sim 30 \%)$ compared with untransfected (ctl) and NC-transfected cells (Fig. 5A; $P<0.05)$.

Also, transfecting hFOB1.19 cells with si-RNF4 alone had no effect on PML expression or sumoylation (Fig. 5B and 3D) and treatment with ATO increased expression and sumoylation of PML compared with control and NC-transfected cells (Fig. 5B). However, pre-transfection with si-RNF4 increased ATO-induced PML expression and sumoylation. Similar effects were observed in FBS-treated hFOB1.19 cells (Fig. 5D). Briefly, FBS treatment increased PML expression and sumoylation, which was enhanced by pre-transfection with si-RNF4.

Studies to understand whether RNF4 is important in ATO- and FBS-induced PMLNBs formation revealed that transfection with si-RNF4 alone had no effect on PML-NBs formation, (Fig. 5C and 3E). However, transfection with si-RNF4 but not NC enhanced both ATO- (Fig. 5C) and FBS-induced (Fig. 5E) PML-NBs formation. Thus, RNF4 inhibits ATO- and FBS-induced PML sumoylation and PML-NBs formation.

Knocking down RNF4 enhances ATO- and FBS-induced TGF- $\beta 1$ expression and collagen synthesis

Finally, we investigated whether RNF4 plays a role in ATO-induced upregulation of TGF- $\beta 1$. hFOB1.19 cells transfected with scrambled control (NC)- or RNF4-siRNA and then treated with ATO (Fig. 6A) or FBS (Fig. 6B) were assayed for TGF- $\beta 1$. As expected, transfection with si-RNF4 alone did not change TGF- $\beta 1$ expression and ATO and FBS both increased TGF- $\beta 1$ expression significantly compared with control cells $(P<0.05)$. However, both ATO- and FBS-induced TGF- $\beta 1$ expression was inhibited by pre-transfection with siRNF4 (Fig. 6A and 6B).

Finally, (Fig. 6C) we treated hFOB1.19 cells with either FBS or ATO and noted increased relative collagen content of cells compared with control cells (both $P<0.05$ ). Interestingly, si-RNF4 transfection enhanced ATO-induced TGF- $\beta$ synthesis after $4 \mathrm{~h}$, but not $24 \mathrm{~h}$ and siRNF4 increased FBS-induced TGF- $\beta 1$ synthesis. 


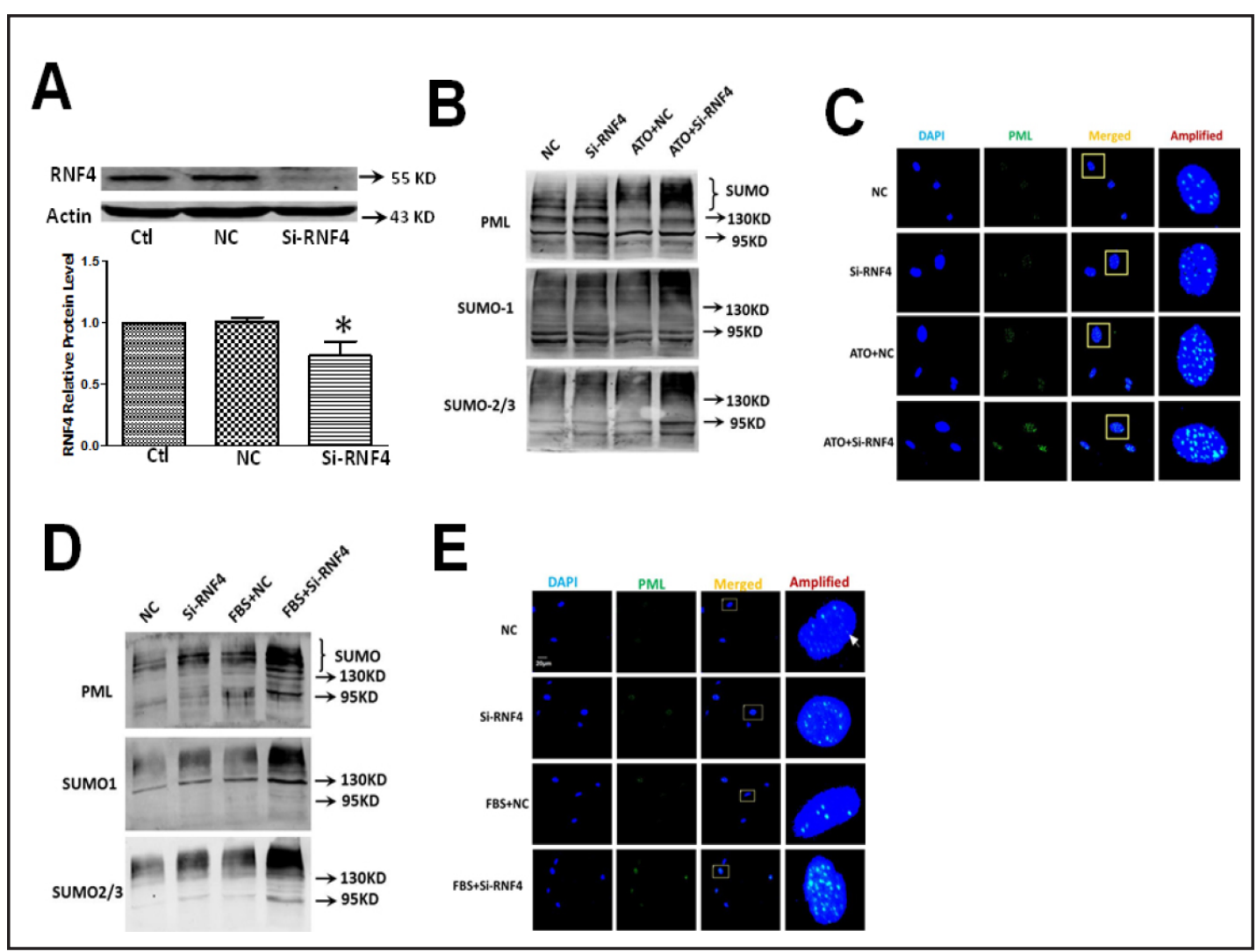

Fig. 5. Successful knockdown of RNF4 using siRNA. hFOB1.19 cells were transfected with scrambled control (NC)- or rnf4-siRNA, and RNF4 expression was measured with Western blot. $\beta$-actin was used as a loading control (A). Knocking down RNF4 promotes ATO- and FBS-induced PML sumoylation. hFOB1.19 cells were transfected as described and treated with ATO (B, C) or FBS (D, E). Western blot depicts PML expression or sumoylation (B, D). PML-NBs formation was measured immunofluorescently (green); sections were counterstained with DAPI (blue) to visualize cell nuclei (C, E), $\mathrm{n}=3$.

\section{Discussion}

Our work confirms that ATO enhanced osteoblast accumulation, and increased collagen synthesis and PML-NBs formation in vivo and in vitro. Knocking down SUMO-conjugating enzyme UBC9 with specific siRNA inhibited ATO- and FBS-induced PML sumoylation and TGF- $\beta 1$ expression. Furthermore, knocking down RNF4, the poly-SUMO-specific E3 ubiquitin ligase required for arsenic-induced PML degradation using siRNA enhanced ATO- and FBSinduced PML sumoylation and TGF- $\beta 1$ expression. In addition, increased PML-NBs formation for serum response was verified [36]. Therefore, we assessed whether osteoblasts can affect the formation of PML-NBs. In hFOB1.19 cells, serum can increase the formation of PML-NBs after sumoylation.

The PML-RAR $\alpha$ fusion protein is found in approximately $98 \%$ of patients with APL [37], so many APL treatments are designed to disrupt or inhibit PML-RAR $\alpha$ downstream signaling [1]. A major treatment modality is all-trans retinoic acid (ATRA) therapy, which is a natural ligand for RARs. ATRA therapy functions by destroying PML-RAR $\alpha$, which eradicates or induces the terminal differentiation of leukemia-initiating cells (LICs). This induces the complete remission in almost all PML-RAR $\alpha$-positive APL patients [36, 38]. However, for patients the ATRA binding site in PML-RAR $\alpha$ becomes mutated, reducing the sensitivity of LICs to ATRA-induced terminal differentiation and causes relapse. Thus, additional treatments are needed [39]. 


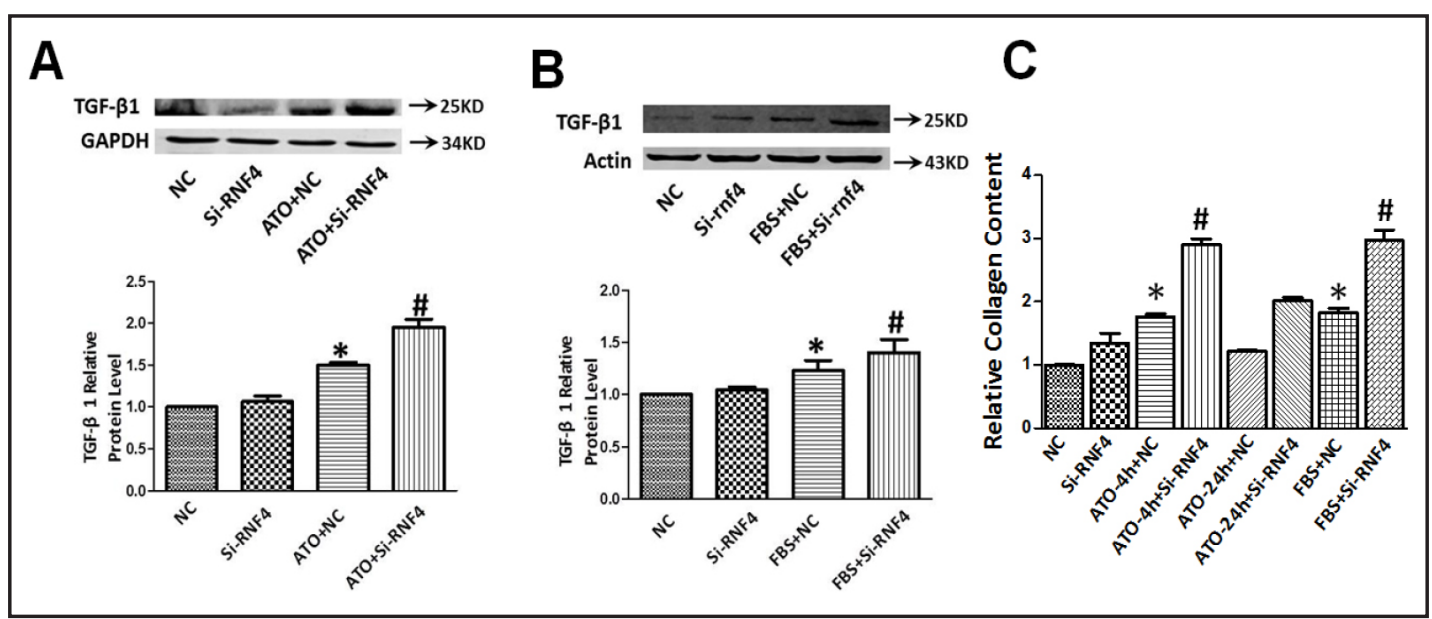

Fig. 6. Knocking down RNF4 enhances ATO- and FBS-induced TGF- $\beta 1$ expression and collagen synthesis. hFOB1.19 cells were transfected with scrambled control (NC)- or RNF4-siRNA and then treated with ATO (A) or FBS (B). Then, TGF- $\beta 1$ was measured with Western blot (A, B), and collagen synthesis was measured as described (C). *, $P<0.05$ vs NC; \#, $P<0.05$ vs ATO+NC, $\mathrm{n}=3$.

ATO is a highly effective treatment for APL, often used to treat relapsing patients after first-line ATRA therapy [10]. For ATO-treated APL, patients undergoing induction therapy receive daily infusions of ATO $(0.15 \mathrm{mg} / \mathrm{kg})$ until achieving bone marrow remission, or for a maximum of 28 days. Pharmacokinetic data indicate that mouse plasma concentration increased after administration of ATO (1 mg/kg, a commonly used dose), peaking at 1.5-3.4 mol/L $[21,22,40]$. Recent studies also suggest complete remission for APL patients with combination treatment with ATO and ATRA, compared with $95 \%$ of patients who received ATRA-chemotherapy [40]. Furthermore, 2-year survival rates exceeded those of patients who received ATO-ATRA. Therefore, ATO may have promise but more studies are needed.

A goal of APL front-line treatment is bone marrow remission [41], so the effects therapeis have on bone is important. Bone is a complex tissue comprised of multiple cell types, including osteoclasts, osteoblasts, and osteocytes, and undergoes continuous bone remodeling during renewal and repair [15]. During this process, osteoblasts generate collagen, which contributes to the formation of new bone. Therefore, that ATO can stimulate collagen formation and differentiation in osteoblasts is beneficial, indicating that ATO may offer benefits that ATRA does not [41].

We previously reported that ATO upregulated the expression of TGF- $\beta 1$ protein and promoted collagen synthesis in osteoblasts in vitro, and hypothesized that PML might regulate ATO-induced activation of the TGF- $\beta$ pathway [21]. This work confirmed the mechanism of action of ATO in osteoblasts, and increases our understanding of arsenic as a chemotherapeutic agent to treat bone-related diseases, as well as its safety and toxicity.

\section{Acknowledgments}

This study was supported by the National Natural Science Foundation of China grant (81173051).

\section{Disclosure Statement}

The authors have declared that no competing interests exist. 


\section{Cellular Physiology Cell Physiol Biochem 2015;37:1581-1591 \begin{tabular}{l|l} 
and Biochemistyy & $\begin{array}{l}\text { DOI: 10.1159/000438525 } \\
\text { Published online: November 02, } 2015\end{array}$ \\
\hline
\end{tabular} \\ Xu et al.: PML Sumoylation Regulates Collagen Synthesis}

\section{References}

1 Nakahara F, Weiss CN, Ito K: The role of PML in hematopoietic and leukemic stem cell maintenance. Int J Hematol 2014;100:18-26.

2 Fagioli M, Grignani F, Ferrucci PF, Alcalay M, Mencarelli A, Nicoletti I, Pelicci PG: Effect of the acute promyelocytic leukemia PML/RAR alpha protein on differentiation and survival of myeloid precursors. Leukemia 1994;8:S7-11.

3 Zhang L, Chen QS. Xu PP, Qian Y, Wang AH, Xiao D, Zhao Y, Sheng Y, Wen XQ, Zhao WL: Catechins induced acute promyelocytic leukemia cell apoptosis and triggered PML-RAR $\alpha$ oncoprotein degradation. J Hematol Oncol 2014;7:1-9.

4 Jing Y: The PML-RAR $\alpha$ fusion protein and targeted therapy for acute promyelocytic leukemia. Leuk Lymphoma 2004;45:639-648.

5 Bernardi R, Pandolfi PP: Structure, dynamics and functions of promyelocytic leukaemia nuclear bodies. Nat Rev Mol Cell Biol 2007;8:1006-1016.

6 Tang MK, Liang YJ, Chan JYH, Wong SW, Chen E, Yao Y, Gan JY, Xiao LH, Leung HC, Kung HF, Wang H, Lee KKH: Promyelocytic leukemia (PML) protein plays important roles in regulating cell adhesion, morphology, proliferation and migration. PLoS One 2013;8:e59477.

7 Lin HK, Bergmann S, Pandolfi PP: Deregulated TGF-beta signaling in leukemogenesis. Oncogene 2005;24:5693-5700.

8 Lin HK, Bergmann S, Pandolfi PP: Cytoplasmic PML function in TGF-beta signalling. Nature 2004;431:205211.

9 Emadi A, Gore SD: Arsenic trioxide-an old drug rediscovered. Blood Rev 2010;24:191-199.

10 Alimoghaddam K: A review of arsenic trioxide and acute promyelocytic leukemia. Int J Hematol Oncol Stem Cell Res 2014;8:44.

11 Lanotte M, Martin-Thouvenin V, Najman S, Balerini P, Valensi F, Berger R: NB4, a maturation inducible cell line with $\mathrm{t}(15 ; 17)$ marker isolated from a human acute promyelocytic leukemia (M3). Blood 1991;77:1080-1086.

12 Geoffroy MC, Jaffray EG, Walker KJ, Hay RT: Arsenic-induced SUMO-dependent recruitment of RNF4 into PML nuclear bodies. Mol Biol Cell 2010;21:4227-4239.

13 Wang Y, Dasso M: SUMOylation and deSUMOylation at a glance. J Cell Sci 2009;122:4249-4252.

14 Tan MY, Mu XY, Liu B, Wang Y, Bao ED, Qiu JX, Fan Y: SUMO-specific protease 2 suppresses cell migration and invasion through inhibiting the expression of MMP13 in bladder cancer cells. Cell Physiol Biochem 2013;32:542-548.

15 Brunner M, Jurdic P, Tuckerman JP, Block MR, Bouvard D: New insights into adhesion signaling in bone formation. Int Rev Cell Mol Biol 2013;305:1-68.

16 Chen Y, Chen L, Yin Q, Gao H, Dong P, Zhang X, Kang J: Reciprocal interferences of TNF- $\alpha$ and Wnt1/ $\beta$ catenin signaling axes shift bone marrow-derived stem cells towards osteoblast lineage after ethanol exposure. Cell Physiol Biochem 2013;32:755-765.

17 Jin T, Zhu YL, Li J, Shi J, He XQ Ding J, Xu YQ: Staphylococcal protein A, Panton-Valentine leukocidin and coagulase aggravate the bone loss and bone destruction in osteomyelitis. Cell Physiol Biochem 2013;32:322-333.

18 Hu YC, Cheng HL, Hsieh BS, Huang LW, Huang TC, Chang KL: Arsenic trioxide affects bone remodeling by effects on osteoblast differentiation and function. Bone 2012;50:1406-1415.

19 Hu YC, Hsieh BS, Cheng HL, Huang LW, Huang TC, Huang IY, Chang KL: Osteoblasts survive the arsenic trioxide treatment by activation of ATM-mediated pathway. Biochem Pharmacol 2013;85:1018-1026.

20 Tang CH, Chiu YC, Huang CF, Chen YW, Chen PC: Arsenic induces cell apoptosis in cultured osteoblasts through endoplasmic reticulum stress. Toxicol Appl Pharmacol 2009;241:173-181.

21 Xu WX, Liu Y, Liu SZ, Zhang Y, Qiao GF, Yan J: Arsenic trioxide exerts a double effect on osteoblast growth in vitro. Environ Toxicol Pharmacol 2014;38:412-419.

22 Chu WF, Li C, Qu XF, Zhao D, Wang XL, Yu XR, Cai FL, Liang HH, Zhang Y, Zhao X, Li BX, Qiao GF, Dong DL, Lu YJ, Du ZM, Yang BF: Arsenic-induced interstitial myocardial fibrosis reveals a new insight into druginduced long QT syndrome. Cardiovasc Res 2012;96:90-98. 


\section{Cellular Physiology Cell Physiol Biochem 2015;37:1581-1591 \begin{tabular}{l|l} 
DOI: 10.1159/000438525 & (C) 2015 S. Karger AG, Basel
\end{tabular} www.karger.com/cpb \\ Xu et al.: PML Sumoylation Regulates Collagen Synthesis}

23 Li C, Qu X, Xu W, Qu N, Mei L, Liu Y, Wang XL, Yu XR, Liu ZY, Nie D, Liu Y, Yan JL, Yang BF, Lu YJ, Chu WF: Arsenic trioxide induces cardiac fibroblast apoptosis in vitro and in vivo by up-regulating TGF- $\beta 1$ expression. Toxicol Lett 2013;219:223-230.

24 Zhang XW, Yan XJ, Zhou ZR, Yang FF, Wu ZY, Sun HB, Liang WX, Song AX, Lallemand-Breitenbach V, Jeanne M, Zhang QY, Yang HY, Huang QH, Zhou GB, Tong JH, Zhang Y, Wu JH, Hu HY, de Thé H, Chen SJ, Chen Z: Arsenic trioxide controls the fate of the PML-RARalpha oncoprotein by directly binding PML. Science 2010;328:240-243.

25 Miao D, He B, Karaplis AC, Goltzman D: Parathyroid hormone is essential for normal fetal bone formation. J Clin Invest 2002;109:1173-1182.

26 Sun F, Duan WQ, Zhang Y, Zhang LL, Qile MG, Liu ZY, Qiu F, Zhao D, Lu YJ, Chu WF: Simvastatin alleviates cardiac fibrosis induced by infarction via up-regulation of TGF- $\beta$ receptor III expression. Br J Pharmacol 2015;172:3779-3792.

27 Rego EM, Wang ZG, Peruzzi D, He LZ, Cordon-Cardo C, Pandolfi PP: Role of promyelocytic leukemia (PML) protein in tumor suppression. J Exp Med 2001;193:521-530.

28 Bernardi R, Pandolfi PP: Role of PML and the PML-nuclear body in the control of programmed cell death. Oncogene 2003;22:9048-9057.

29 Hayakawa F, Privalsky ML: Phosphorylation of PML by mitogen-activated protein kinases plays a key role in arsenic trioxide-mediated apoptosis. Cancer Cell 2004;5:389-401.

30 Zhu J, Koken MHM, Quignon F, Chelbi-Alix MK, Degos L, Wang ZY, Chen Z: Arsenic-induced PML targeting onto nuclear bodies: Implications for the treatment of acute promyelocytic leukemia. Proc Natl Acad Sci U S A 1997;94:3978-3983.

31 Weisshaar SR, Keusekotten K, Krause A, Horst C, Springer HM, Göttsche K, Dohmen RJ, Praefcke GJ: Arsenic trioxide stimulates SUMO-2/3 modification leading to RNF4-dependent proteolytic targeting of PML. FEBS Lett 2008;582:3174-3178.

32 Cuchet D, Sykes A, Nicolas A, Orr A, Murray J, Sirma H, Heeren J, Bartelt A, Everett RD: PML isoforms I and II participate in PML-dependent restriction of HSV-1 replication. J Cell Sci 2011;124:280-291.

33 Hands KJ, Cuchet-Lourenco D, Everett RD, Hay RT: PML isoforms in response to arsenic: high-resolution analysis of PML body structure and degradation. J Cell Sci 2014;127:365-375.

34 Sampson DA, Wang M, Matunis MJ: The small ubiquitin-like modifier-1 (SUMO-1) consensus sequence mediates Ubc9 binding and is essential for SUMO-1 modification. J Biol Chem 2001;276:21664-21669.

35 Lin X, Liang M, Liang YY, Brunicardi FC, Feng XH: SUMO-1/Ubc9 promotes nuclear accumulation and metabolic stability of tumor suppressor Smad4. J Biol Chem 2003;278:31043-31048.

36 Nasr R, Guillemin MC, Ferhi O, Soilihi H, Peres L, Berthier C, Rousselot P, Robledo-Sarmiento M, LallemandBreitenbach V, Gourmel B, Vitoux D, Pandolfi PP, Rochette-Egly C, Zhu J, de Thé H: Eradication of acute promyelocytic leukemia-initiating cells through PML-RARA degradation. Nat Med 2008;14:1333-1342.

37 He LZ, Tribioli C, Rivi R, Peruzzi D, Pelicci PG, Soares V, Cattoretti G, Pandolfi PP: Acute leukemia with promyelocytic features in PML/RAR transgenic mice. Proc Natl Acad Sci U S A 1997;94:5302-5307.

38 Gu ZM, Wu YL, Zhou MY, Liu CX, Xu HZ, Yan H, Zhao Y, Huang Y, Sun HD, Chen GQ: Pharicin B stabilizes retinoic acid receptor- $\alpha$ and presents synergistic differentiation induction with ATRA in myeloid leukemic cells. Blood 2010;116:5289-5297.

39 Gallagher RE: Retinoic acid resistance in acute promyelocytic leukemia. Leukemia 2002;16:1940-1958.

40 Lo-Coco F, Avvisati G, Vignetti M, Thiede C, Orlando SM, Iacobelli S, Ferrara F, Fazi P, Cicconi L, Di Bona E, Specchia G, Sica S, Divona M, Levis A, Fiedler W, Cerqui E, Breccia M, Fioritoni G, Salih HR, Cazzola M, Melillo L, Carella AM, Brandts CH, Morra E, von Lilienfeld-Toal M, Hertenstein B, Wattad M, Lübbert M, Hänel M, Schmitz N, Link H, Kropp MG, Rambaldi A, La Nasa G, Luppi M, Ciceri F, Finizio O, Venditti A, Fabbiano F, Döhner K, Sauer M, Ganser A, Amadori S, Mandelli F, Döhner H, Ehninger G, Schlenk RF, Platzbecker, U: Retinoic acid and arsenic trioxide for acute promyelocytic leukemia. N Engl J Med 2013;369:111-121.

41 Notario A, Rolandi ML, Mazzucchelli I: Peripheral blood and bone marrow changes after treatment with ATRA and G-CSF in AML, APL and blast crisis following Vaquez's disease. Haematologica 1996;81:261-264. 